\title{
Knowledge, attitudes and breast-feeding practices of postnatal mothers in Central India
}

\author{
Jayant V. Upadhye ${ }^{1}$, Milind R. Mandlik ${ }^{1}$, Aditi J. Upadhye², Sanjay M. Marathe1, \\ Abhay R. Matte ${ }^{1}$, Jayshree J. Upadhye ${ }^{3 *}$
}

\begin{abstract}
${ }^{1}$ Consultant Paediatrician and Neonatologist, Colours Children Hospital, Nagpur, Maharashtra, India
${ }^{2}$ Department of Pathology, PDMMC, Amravati, Maharashtra, India

${ }^{3}$ Department of Obstetrics and Gynecology, Rajshree Medical College, Bareilly, Uttar Pradesh, India
\end{abstract}

Received: 31 July 2018

Accepted: 04 August 2018

\section{*Correspondence:}

Dr. Jayshree J. Upadhye,

E-mail: jayshreeupadhye@gmail.com

Copyright: () the author(s), publisher and licensee Medip Academy. This is an open-access article distributed under the terms of the Creative Commons Attribution Non-Commercial License, which permits unrestricted non-commercial use, distribution, and reproduction in any medium, provided the original work is properly cited.

\begin{abstract}
Background: Breast feeding is vital for the health of baby \& mother. It is of advantage to baby, mother, family, society and nation. Present study was carried out to evaluate knowledge, attitude and breast feeding practices of postnatal women.

Methods: This cross-sectional study was carried out at immunization centre. 208 postnatal women were interviewed. Results: Out of 208 postnatal women, 148 women $(71.15 \%)$ had delivery by caesarean section while 60 women $(28.84 \%)$ had vaginal delivery. 118 women $(56.73 \%)$ started breast feeding the baby within 2 hours of delivery, 52 women $(25 \%)$ started breast feeding the baby after 24 hours of delivery, 26 women $(12.5 \%)$ started breast feeding the baby after 2-6 hours of delivery while 12 women $(5.76 \%)$ started breast feeding the baby after 6-24 hours of delivery. 174 women $(83.65 \%)$ were giving exclusive breast feeding to their babies, 32 women $(15.38 \%)$ were giving mixed feeding to their babies due to failure to thrive because of inadequate breast secretions. $28(13.46 \%)$ preferred to give formula feeds while $7(3.36 \%)$ preferred to give cow's milk when needed. $180(86.53 \%)$ intend or started weaning after 6 months while 28 women (13.46\%) started weaning to their babies due to failure of baby to thrive or inadequate lactation.

Conclusions: Awareness of breast feeding was good. Majority preferred exclusive breast feeding. Still, antenatal counseling about breast feeding can be further of advantage.
\end{abstract}

Keywords: Attitude, Breast feeding, India, Infant feeding practices, Knowledge, Mothers

\section{INTRODUCTION}

Breastfeeding is vital to infant and maternal health and of immense economic value to households and societies. Breast feeding offers several benefits for both the infants and mothers.

Despite strong evidences in support of breast feeding, its prevalence has remained low worldwide. ${ }^{1}$ The WHO recommends that infants should be exclusively breastfed for the first six months to achieve optimal growth, development, and health. Then, infants should receive nutritionally adequate and safe complementary foods, with continued breastfeed for up to two years or more. ${ }^{2}$

Exclusive breast feeding is defined as infant feeding with human milk without the addition of any other liquids or solid food. ${ }^{3}$ 
Though the health benefits of breastfeeding are well documented and initiation rates have increased over the past 20 years, most mothers wean before 6-months postpartum because of difficulties with breastfeeding rather than due to maternal choice. Women less likely to breastfeed are those who are young, belong to an ethnic minority, are unsupported, are employed full-time, decided to breastfeed during or late in pregnancy, have negative attitudes toward breastfeeding, and have low confidence in their ability to breastfeed. Support from the partner or a nonprofessional increases the likelihood of positive breastfeeding behaviors. Health care professionals can be a negative source of support if due to lack of knowledge, they give inaccurate or inconsistent advice. Also, a number of hospital routines are potentially detrimental to breastfeeding. ${ }^{4}$

Breastfeeding is associated with beneficial health for both the child and mother. Multiple US-based and international organizations recommend exclusive breastfeeding for 6 months, followed by continued breastfeeding along with complementary feeds for at least 1 year as mutually desired by mother and infant. ${ }^{5}$

Breast feeding serves multiple purposes to the growing baby, mother, and also the whole family. It significantly reduces mortality in neonatal sepsis, pneumonia, and diarrhea what was reported in Lancet's "Child Survival Series" 2003. The only effective preventive intervention to decrease $13-15 \%$ of child deaths is by implementing universal breastfeeding. This with adequate complementary feeding would prevent $19 \%$ of child deaths (Lancet 2003, 2005). ${ }^{6}$

Many reports suggest that the incidence of breastfeeding is declining in all parts of the world probably because of increasing modernization, introduction of artificial feeds, and early initiation of complimentary feeds. This could be attributed to increasing educational levels, with mothers being more employed. ${ }^{6}$

Discarding colostrum and delayed initiation of breastfeeding because of various reasons are still practiced in few communities. Early and unnecessary introduction of top feeding in incorrect dilutions and in unhygienic pattern are also prevalent. The key to successful breastfeeding is continuous vigilance over infant feeding practice in the community to ensure optimal growth and development in the infant. ${ }^{6}$

One of the most important determinants of child survival, birth spacing, and prevention of childhood infections is Breastfeeding. ${ }^{7}$

The beneficial effects of breastfeeding depend on breastfeeding initiation, its duration, and the age at which weaning of the breast-fed child is done. ${ }^{7}$

In India, according to National Family Health Survey (NFHS 3) report, only $46 \%$ infants who are under six months are exclusively breastfed and only 55\% are initiated on breastfeed on day one. ${ }^{8}$

Education has made more and more women economically independent and busy professionals. In modern India nuclear families are becoming quite common. Missing traditional family values and peer support for women might have a negative impact on the preservation of valuable breastfeeding practices in Indian population. ${ }^{8}$

It is estimated that sub-optimal breastfeeding, especially non-exclusive breastfeeding in the first 6 months of life, results in 1.4 million deaths and $10 \%$ of the disease burden in children less than 5 years of age. ${ }^{9}$

Mother's milk is one of the most important determinants in inter birth spacing and prevention of childhood infections. Breast milk provides nutritive and immunological protection in infants to ensure health as well as survival. It prevents adult onset diseases like coronary artery disease, diabetes and hypertension. ${ }^{10}$

In India, more than 11 lakh babies die during the first month of life, and 5 lakhs die during 2 to 12 months of age. Neonatal mortality accounts for $40 \%$ of under-five deaths and $60 \%$ of infant deaths. $80-90 \%$ of mothers believe that the first milk which is watery and light yellowish in color is a secretion collected over nine months and will be harmful to the neonate. So, they squeeze the first milk and discard it and initiate breastfeeding only after two to three days. ${ }^{11}$

The present study was designed to explore the perceptions and practices related to breastfeeding among postnatal mothers. This information will be useful to policy makers for the formulation of future interventional programs.

The aim and objective of the present study was to evaluate the knowledge and attitude towards breast feeding and infant feeding practices among Indian postnatal mothers.

\section{METHODS}

A cross sectional descriptive study was carried out among randomly selected 208 postnatal mothers at immunisation outpatient department of Colours Children Hospital, Nagpur from January to December in year 2017.

\section{Inclusion criteria}

- Postnatal women within one year of delivery

- Women who have given consent for participation in the study.

\section{Exclusion criteria}

Women who did not give consent for participation in the study. 
Data was collected through face-to-face interview using a structured questionnaire and analysed.

Table 1: Questionnaire.

\begin{tabular}{|ll|}
\hline Number & Variables \\
\hline 1 & Age \\
\hline 2 & Parity \\
\hline 3 & $\begin{array}{l}\text { Mode of delivery- vaginal or caesarean } \\
\text { section }\end{array}$ \\
\hline 4 & \begin{tabular}{l} 
Time of initiation after delivery \\
\hline 5
\end{tabular} \\
\hline 6 & $\begin{array}{l}\text { Whether prelacteal feeds were given and } \\
\text { What }\end{array}$ \\
\hline 7 & $\begin{array}{l}\text { Whether exclusive breast feeding was } \\
\text { given }\end{array}$ \\
\hline 8 & Perception about exclusive breast feeding \\
\hline 9 & Age at which weaning was done \\
\hline
\end{tabular}

\section{RESULTS}

In present study, 88 women $(42.30 \%)$ were between 21 25 years, 58 women $(27.88 \%)$ were between $26-30$ years, 36 women $(17.30 \%)$ were between $31-35$ years, 14 women $(6.730 \%)$ were above 35 years of age while 12 women $(5.769 \%)$ were of less than 20 years of age (Table 2).

\section{Table 2: Age distribution.}

\begin{tabular}{|c|c|c|}
\hline $\begin{array}{l}\text { Age } \\
\text { distribution }\end{array}$ & $\begin{array}{l}\text { No. of postnatal } \\
\text { women }\end{array}$ & Percentage \\
\hline$<20$ years & 12 & 5.769 \\
\hline $21-25$ years & 88 & 42.30 \\
\hline $26-30$ years & 58 & 27.88 \\
\hline $31-35$ years & 36 & 17.30 \\
\hline$>35$ years & 14 & 6.730 \\
\hline Total & 208 & 100 \\
\hline
\end{tabular}

In present study, 160 women $(76.92 \%)$ were Primipara while 48 women $(23.07 \%)$ were Multipara (Table 3).

Table 3: Parity.

\begin{tabular}{|lll|}
\hline Parity & No. of postnatal women & Percentage \\
\hline Primipara & 160 & 76.92 \\
\hline Multipara & 48 & 23.07 \\
\hline
\end{tabular}

In present study, 148 women $(71.15 \%)$ had delivery by caesarean section while 60 women $(28.84 \%)$ had vaginal delivery (Table 4).

Table 4: Mode of delivery.

\begin{tabular}{|lll|}
\hline Mode of delivery & $\begin{array}{l}\text { No. of postnatal } \\
\text { women }\end{array}$ & Percentage \\
\hline Caesarean section & 148 & 71.15 \\
\hline Vaginal delivery & 60 & 28.84 \\
\hline
\end{tabular}

Table 5: Initiation of breast feeding.

\begin{tabular}{|lll|}
\hline $\begin{array}{l}\text { Initiation of breast } \\
\text { feeding }\end{array}$ & $\begin{array}{l}\text { No. of postnatal } \\
\text { women }\end{array}$ & Percentage \\
\hline Within 2 hours & 118 & 56.73 \\
\hline 2-6 hours & 26 & 12.5 \\
\hline 6-24 hours & 12 & 5.76 \\
\hline$>24$ hours & 52 & 25 \\
\hline
\end{tabular}

In present study, 118 women $(56.73 \%)$ started breast feeding the baby within 2 hours of delivery, 52 women $(25 \%)$ started breast feeding the baby after 24 hours of delivery, 26 women $(12.5 \%)$ started breast feeding the baby within 2-6 hours of delivery while 12 women $(5.76 \%)$ started breast feeding the baby within 6-24 hours of delivery (Table 5).

Table 6: Type of feeding.

\begin{tabular}{|lll|}
\hline Type of feeding & $\begin{array}{l}\text { No. of postnatal } \\
\text { women }\end{array}$ & Percentage \\
\hline $\begin{array}{l}\text { Exclusive breast } \\
\text { feeding }\end{array}$ & 174 & 83.65 \\
\hline Mixed & 32 & 15.38 \\
\hline Top feeding only & 3 & 1.442 \\
\hline
\end{tabular}

Reasons for delaying initiation of breast feeding were baby in premature baby unit, women under sedation after cesarean section and myths about not giving colostrums.

In present study, awareness about exclusive breast feeding was quite good. 174 women (83.65\%) were giving exclusive breast feeding to their babies, 32 women $(15.38 \%)$ were giving mixed feeding to their babies due to failure to thrive because of inadequate secretion.

Table 7: Type of feeding.

\begin{tabular}{|lll|}
\hline $\begin{array}{l}\text { Type of Top } \\
\text { feeding }\end{array}$ & No. of postnatal & Percentage \\
\hline Fomen & 28 & 13.46 \\
\hline Cow's milk & 7 & 3.365 \\
\hline
\end{tabular}

Table 8: Period of weaning.

\begin{tabular}{|lll|}
$\begin{array}{l}\text { Period of } \\
\text { weaning }\end{array}$ & $\begin{array}{l}\text { No. of postnatal } \\
\text { women }\end{array}$ & Percentage \\
\hline$>6$ months & 180 & 86.53 \\
\hline$<6$ months & 28 & 13.465 \\
\hline
\end{tabular}

3 women $(1.442 \%)$ were giving total top feeds to their babies. Out of this, 2 mothers had failure of lactation and 1 had adopted the baby (Table 6). In present study, majority women i.e. $28(13.46 \%)$ preferred to give formula feeds while $7(3.36 \%)$ preferred to give cow's milk when needed (Table 7). In present study, majority women i.e. $180(86.53 \%)$ intend or started weaning after 6 months while 28 women $(13.46 \%)$ started weaning to their babies due to failure of baby to thrive or inadequate lactation (Table 8). 


\section{DISCUSSION}

In present study, 88 women $(42.30 \%)$ were between 21 25 years, 58 women $(27.88 \%)$ were between $26-30$ years, 36 women $(17.30 \%)$ were between $31-35$ years, 14 women $(6.730 \%)$ were above 35 years of age while 12 women $(5.769 \%)$ were of less than 20 years of age (Table 2).

Madhu $\mathrm{K}$ et al reported that majority of the mothers were between the ages of 21 and 25 years old $(60 \%)$ and $30 \%$ were between 15 and 20 years. $^{7}$

Anindita $\mathrm{M}$ found that majority of the lactating mothers were between the ages of 21 and 25 years $(60 \%)$, and 26 and 36 years $(30 \%){ }^{10}$

In present study, 160 women $(76.92 \%)$ were Primipara while 48 women $(23.07 \%)$ were Multipara (Table 3). Anindita M found that $65 \%$ mothers were primigravidae. ${ }^{10}$

In our study, 148 women (71.15\%) had delivery by caesarean section while 60 women $(28.84 \%)$ had vaginal delivery (Table 4).

In present study, 118 women $(56.73 \%)$ started breast feeding the baby within 2 hours of delivery, 52 women $(25 \%)$ started breast feeding the baby after 24 hours of delivery, 26 women $(12.5 \%)$ started breast feeding the baby within 2-6 hours of delivery while 12 women $(5.76 \%)$ started breast feeding the baby within 6-24 hours of delivery (Table 5).

Singh J found that 208 (74\%) of mothers initiated breastfeeding within $6 \mathrm{~h}$ and at least $05(1.7 \%)$ had initiated it in 25-72 hrs. $^{11}$

In present study, awareness about exclusive breast feeding was quite good. 174 women (83.65\%) were giving exclusive breast feeding to their babies, 32 women $(15.38 \%)$ were giving mixed feeding to their babies due to failure to thrive because of inadequate secretion. 3 women $(1.442 \%)$ were giving total top feeds to their babies. Out of this, 2 mothers had failure of lactation and 1 had adopted the baby (Table 6).

Singh J found that $124(44 \%)$ of mothers were breastfeeding their baby every $4 \mathrm{~h}$, a few 36 (12\%) mothers had breastfed their babies as per elderly advice, and the remaining $2 \%$ had other frequencies for breastfeeding. ${ }^{11}$

In present study, majority women i.e. 28 (13.46\%) preferred to give formula feeds while $7(3.36 \%)$ preferred to give cow's milk when needed (Table 7).

Singh $\mathrm{J}$ found that $47 \%$ mothers were giving only breast milk and still there were two popular methods being practiced by the mothers in study are honey (23\%) and ghutti (10\%) (baljanma ghutti). Many of the mothers were using plain sugar water and artificial milk also as a substitute.

In present study, majority women i.e. 180 (86.53\%) intend or started weaning after 6 months while 28 women $(13.46 \%)$ started weaning to their babies due to failure of baby to thrive or inadequate lactation (Table 8).

Singh J found that majority 225 (80\%) of the mothers had breastfed their baby for more than six months and 55 $(19.6 \%)$ mothers had breastfed their child for less than six months. ${ }^{11}$

\section{CONCLUSION}

Importance of breastfeeding, practices of early initiation and exclusive breastfeeding, and their perceptions towards breastfeeding were fairly satisfactory among mothers included in this study. This study emphasizes the need for breastfeeding intervention programs especially for the mother during antenatal and postnatal check-ups. The information regarding the advantages and duration of breastfeeding needs to be provided for the community as a whole.

\section{Funding: No funding sources}

Conflict of interest: None declared

Ethical approval: The study was approved by the Institutional Ethics Committee

\section{REFERENCES}

1. Vijayalakshmi P, Susheela T, Mythili D. Knowledge, attitudes, and breast feeding practices of postnatal mothers: a cross sectional survey. Int J of Health Sci. 2015 Oct;9(4):364.

2. WHO. Exclusive breast feeding for six months is best for babies everywhere'. World Health Organization 2011. (Cited 2014 July 21). Available at: http://www.who.int.

3. WHO. The WHO Global Data Bank on Infant and Young Child Feeding. WHO Nutrition for Health and Development; 2009. (Cited 2014 July 21). Available at: http://www.who.int.

4. Dennis CL. Breastfeeding initiation and duration: A 1990-2000 literature review. J Obstet Gynecol Neonatal Nursing. 2002 Jan;31(1):12-32.

5. Carrie D. Patnode, Michelle L. Henninger, Caitlyn A. Senger, Review for the US Preventive Services Task Force, JAMA. 2016;316(16):1694-1705.

6. Kamath SP, Garg D, Khan M, Jain A, Baliga BS. Perceptions and practices regarding breastfeeding among postnatal women at a District Tertiary Referral Government Hospital in Southern India. Scientifica. 2016;2016.

7. Madhu K, Chowdary S, Masthi R. Breast feeding practices and newborn care in rural areas: a descriptive cross-sectional study. Indian J Comm 
Med: official publication of Indian Association of Preventive Social Medicine. 2009 Jul;34(3):243.

8. Pandey D, Sardana P, Saxena A, Dogra L, Coondoo A, Kamath A. Awareness and attitude towards breastfeeding among two generations of indian women: a comparative study. PloS one. 2015 May 19;10(5):e0126575.

9. Ekambaram M, Bhat V, Ahamed MA. Knowledge, attitiude and practice of breastfeeding among postnatal mothers. Current Pediatr Res. 2010;14(2).

10. Maiti A, Sarangi L, Sahu SK, Mohanty SS. An assessment on breastfeeding and weaning practices in Odisha, India. Am J Public Health Res. 2015;3(4A):49-52.
11. Singh J, Vishakantamurthy DG, Charan PM. Breastfeeding practices among lactating mothers: Problems and prospects in a cross-sectional study. Int J Health Allied Sci. 2012 Apr 1;1(2):54.

Cite this article as: Upadhye JV, Mandlik MR, Upadhye AJ, Marathe SM, Matte AR, Upadhye JJ. Knowledge, attitudes and breast feeding practices of postnatal mothers in Central India. Int J Reprod Contracept Obstet Gynecol 2018;7:3546-50. 